\title{
PREVALENSI LABIOSCHISIS DI RSUP. PROF. Dr. R. D. KANDOU MANADO PERIODE JANUARI 2011 - OKTOBER 2012
}

\author{
Jilly Natalia Loho \\ Bagian Bedah Fakultas Kedokteran Universitas Sam Ratulangi Manado \\ Email: jilly.loho@ymail.com
}

\begin{abstract}
Cleft lip or labioschisis is an inherited disorder that can occur on the lips to the ceiling. Cleft lip is a disruption in the face of growth since the fourth week of embryonic life. Method: This research in retrospection description research for knowning prevalence cleft lip or labioschisis in surgical department RSUP. Prof. Dr. R. D. Kandou Manado, period of Januari 2011 - October 2012. Output: Prevalence of Labioschisis and Labiopalatochisis on Januari 2011 - October 2012 is 57\% and $43 \%$. Presentation for each of kind harelipped are : unilateral labioschisis $47 \%$, bilateral labioschisis $5 \%$, unilateral palatum of labioshisis $28 \%$, and bilateral palatum of labioschisis $12 \%$, submucosa $1 \%$, and cleft palate lips $7 \%$. Presentation according to the place of defect : right $18 \%$, left $57 \%$, bilateral $25 \%$, and status not complete $54 \%$. Presentation according to age for doing operation : $0-4$ years $73 \%$, 5-9 years $10 \%, 10-14$ years $7 \%$, and $>15$ years $10 \%$. Presentation labioschisis according to sex : Man 58\%, and women 42\%. Presentation labioschisis according to etiology : genetic factor 25\%, environment factor 62\%, and unknown factor $13 \%$. Presentation of labioschisis that be surgery 93\%, and not surgery 7\%. Presentation of labioschisis according to complication surgery : bleeding post surgery $1 \%$, secunder infection $4 \%$, dehisensi/establish scar $4 \%$, and not complication 91\%. Conclusion: Prevalence labioschisis still decrease in each year, kind of labioschisis that large is unilateral labioschisis and localization defect is often on left edge. Labioschisis is happen more to man. Factor that to cause labioschisis between : genetic factor, environment factor and unknown factor. Labioschisis is often more to surgery 0-4 years old.
\end{abstract}

Keywords: Prevalence cleft lip or labioschisis.

\begin{abstract}
Abstrak: Labioschisis adalah suatu kelainan bawaan yang terjadi pada bibir yang dapat sampai pada langit - langit. Bibir sumbing merupakan suatu gangguan pada pertumbuhan wajah sejak embrio umur minggu ke empat. Metode: Penelitian ini merupakan peneitian deskriptif retrospektif untuk mengetahui prevalensi bibir sumbing atau labioschisis di Bagian Bedah RSUP. Prof. Dr. R. D. Kandou Manado periode Januari 2011 - Oktober 2012. Hasil: Prevalensi labioschisis dan labiopalatoschisis pada Januari 2011 - Oktober 2012 yaitu 57\% dan 43\%. Persentase untuk tiap jenis kesumbingan adalah sebagai berikut, bibir sumbing unilateral $47 \%$, bibir sumbing bilateral 5\%, bibir sumbing langit - langit unilateral $28 \%$, bibir sumbing langit - langit bilateral 12 , sumukosa $1 \%$, dan sumbing bibir langit - langit 7\%. Persentase menurut lokalisasi defek adalah kanan 18\%, kiri 57\%, bilateral 25\%, dan status tidak lengkap 54\%. Persentase menurut umur saat dilakukan operasi adalah 0-4 tahun 73\%, 5-9 tahun 10\%, 10-14 tahun 7\%, dan >15 tahun 10\%. Persentase labioschisis menurut jenis kelamin adalah Pria 58\%, dan Wanita 42\%. Persentase labioschisis menurut etiologi adalah faktor genetik 25\%, faktor lingkungan 62\%, dan faktor unknown 13\%. Persentase labioschisis yang dioperasi adalah dioperasi 97\%, dan tidak dioperasi 3\%. Persentase labioschisis menurut komplikasi operasi adalah perdarahan pascaoperasi $1 \%$, infeksi sekunder $4 \%$, dehisensi/pembentukan parut 4\%, dan tidak ada kompliaksi 91\%. Kesimpulan: Prevalensi bibir sumbing atau labioschisis semakin menurun tiap tahun, jenis kesumbingan terbanyak adalah bibir sumbing unilateral dan lokalisasi defek tersering adalah pada sisi kiri. Bibir sumbing atau labioschisis sering terjadi pada laki - laki. Faktor yang menyebabkan terjadinya kesumbingan antara lain: faktor genetik, faktor lingkungan, dan faktor unknown. Labioschisis paling banyak dioperasi umur 0-4 tahun.
\end{abstract}

Kata kunci: Prevalensi bibir sumbing atau labioschisis. 
Bibir sumbing adalah salah satu cacat lahir yang paling banyak dijumpai didunia ini. Sumbing adalah kondisi terbelah pada bibir yang dapat sampai pada langit - langit, akibat dari embriologi perkembangan struktur wajah yang mengalami gangguan. ${ }^{1}$ Bibir sumbing atau Labioschisis adalah suatu kelainan bawaan yang terjadi pada bibir bagian yang dapat disertai kelainan pada langit-langit. Bibir sumbing merupakan suatu gangguan pada pertumbuhan wajah sejak embrio umur minggu ke IV. ${ }^{2}$

Insiden bibir sumbing atau Labioschisi sebanyak 2,1 dalam 1000 kelahiran pada etnis Asia, 1:1000 pada etnis Kaukasia, dan 0,41:1000 pada etnis Afrika-Amerika. Insiden tertinggi terdapat pada orang Asia dan terendah pada kulit hitam. Labioschisis lebih sering terjadi pada laki - laki. ${ }^{4}$ Insiden bibir sumbing atau Labioschisis di Indonesia belum diketahui. $^{5}$

Celah pada bibir disebabkan oleh kegagalan perkembangan dan penyatuan processus frontonasal dan processus maxilaris. Bibir sumbing bisa terdapat pada satu sisi atau kedua sisi dari garis tengah. Biasanya sumbing bibir sisi kiri lebih sering ditemukan dari pada sisi kanan. Karena vaskularisasi sisi kanan lebih baik, sehingga sumbing sisi kanan lebih dahulu mencapai bagian medial. Pria lebih sering terjadi sumbing dari pada wanita. Karena wanita memiliki vaskularisasi yg lebih baik, sehingga wanita lebih cepat terjadi penutupan dari pada pria. ${ }^{8}$

Kelainan bibir terdiri atas berbagai macam, diantaranya bibir sumbing (Labioschisis), sumbing atau celah pada langitlangit rongga mulut (Palatoschisis), atau pun gabungan dari keduanya berupa sumbing bibir dan langitan (Labiopalatoschisis), dan sumbing bibir sampai gusi dan langit-langit (Labiogenatopalatoschisis). Kelainan tersebut juga biasa terjadi pada satu sisi rahang (unilateral) ataupun pada kedua sisi yaitu kanan dan kiri (bilateral).

Pembentukannya dimulai pd minggu ke 4 kehamilan. Peristiwa ini terjadi di rahim. Pembentukannya dibagi 2 pusat pertumbuhan, yaitu :1) Palatum primer yang terletak didepan dari foramen incisivum, untuk membentuk alveolus dan labium. 2) Palatum sekunder dibelakang dari foramen incisivum, untuk membentuk palatum durum/molle dan uvula. Palatum sekunder akan membentuk bagian besar palatum durum dan palatum mole. ${ }^{11}$

Etiologi bibir sumbing atau Labioschisis dan sumbing palatum Palatoschisis telah diketahui, tetapi sepertinya merupakan kombinasi multifaktor antara faktor genetik dan faktor lingkungan: ${ }^{13}$ 1) Genetik 22\%: Faktor ini biasanya diturunkan secara genetik dari riwayat keluarga yang mengalami mutasi genetik. Oleh karena itu penting sekali saat proses anamnesa dengan pasien untuk menanyakan soal apakah ada riwayat keturunan dari keluarga soal kelainan ini. 2) Lingkungan 78\%: Faktorfaktor yang dapat mempengaruhi proses kehamilan, lebih karena faktor obat-obatan yang bersifat teratogen semasa kehamilan, misalnya; asetosal atau aspirin. Beberapa faktor yang mempengaruhi bibir sumbing dan langit-langit seperti geografi, ras, jenis kelamin, budaya, dan juga sosial ekonomi. Pertumbuhan latar belakang ekonomi dan industri, dan budaya adalah faktor dominan pada proses penyakit atau anomali selama fase embryologik. Anomaly dalam fase embrionik dan fase janin latar belakang dan masalah bibir sumbing langit-langit. ${ }^{15}$

Kesumbingan pada Bibir \& Langitlangit termasuk bagian dari kesumbingan pada wajah, ini adalah suatu bentuk kelainan bawaan sejak lahir, dimana terjadi gangguan proses pertumbuhan Embryonal, sehingga tidak terjadinya fusi antara prosesus frontonasal pada bagian medial dan prosesus maxilaris dari kedua sisi lateral kepala. Manifestasi klinis: berupa celah pada bibir yang dapat sampai langitlangit dengan segala kemungkinannya, yang bisa komplit/inkomplit, bisa unilateral/bilateral yang disertai dengan distorsi jaringan sekitar (hidung dll). Pemeriksaan tambahan pada saat hamil: USG 3D, untuk memvisualisasikan bibir sumbing dan normal.

Penanganan hanya dengan operasi, beberapa cara penanganan sumbing untuk mendekatkan sebelum operasi, yaitu: 
1. KONSERVATIP: 1) Dengan plester atau elastic bands (Head Cap traction). 2) Dengan atur posisi tidur : tengkurap dengan miring kesisi lesi, untuk mendekatkan gap, tetapi hati-hati karena bayi dapat mati tiba-tiba.

2. AGGRESSIVE: 1) Dengan cara Letham. 2) Operasi approximasi simple segera, bisa merusak pertumbuhan. 3) Wiring dental arch: lama dan dengan active appliance with screw hasilnya bisa sama, 4) Terapi dengan memperbaiki gangguan pada chromosome.

Penanganan menyeluruh, yaitu: Dengan menerangkan pada orang tua tentang hal berikut: Penanganan dengan memperhatikan. $^{7}$

1) Diagnosa: Harus dijelaskan pada orang tua pasien tentang diagnosa yang ada. Berdasarkan diagnosa yaitu : Sumbing bibir, sumbing wajah, sumbing yang syndromatik, sumbing yang non syndromatik. Sebab beda penanganan sumbing bibir dan sumbing wajah. Penanganan emergency Sumbing dengan syndrome, yaitu, mis: Piere Robin Syndrome dengan sumbing (mikrognasia), tindakan yang ini dengan fiksasi lidah. Pada sumbing syndrome synostosis dengan gangguan pernapasan dan napas yang berbunyi tindakannya adalah palatoplasty.

2) Problematika: Gangguan fungsi: Pertumbuhan, pernafasan, bicara, pendengaran. Gangguan estetis, Gangguan psikis.

3) Penyebab: Genetik (turunan), gangguan pada gen (tunggal), gangguan pada Chromosome. Aqcuired (didapat).: Akibat deficiency micronutrien, akibat bahanbahan teratogenik, akibat trauma / Infeksi, akibat mutasi gen (multifaktorial).

4) Penanganan. Tindakan operasi sesuai rule over ten: - $\mathrm{BB}>10$ pon (5kg), - Hb $>10 \%$, - usia >10minggu. Dengan memperhatikan: Faktor Emergency, faktor Psychis orang tua dan anak. , faktor Keserasian pertumbuhan jaringan, faktor
Fungsi jaringan/organ, faktor Estetika, waktu operasi.

5) Pencegahan: Hindari Kawin Keluarga, Hindari Kawin dengan Sumbing, Hindari Bahan yang Teratogenik, Hindari stress / trauma psikis/fisik, Lengkapi kebutuhan makanan harian.

Komplikasi yang dapat terjadi pascaoperasi cheilonasoraphy dan paltoraphy, yaitu ${ }^{8}$ : Perdarahan, infeksi, wound dehiscense, hematoma dan dapat terjadi obstruksi jalan nafas.

\section{METODE PENELITIAN}

Jenis penelitian ini bersifat retrospektif-deskriptif. Subjek penelitian adalah semua pasien penderita Labioschisis yang di rawat di RSUP Prof. Dr. R. D. Kandou Manado. Tempat penelitian adalah di Bagian Rekam Medik. Penelitian dilakukan pada bulan Januari 2011 Oktober 2012. Data berupa rekam medik.

\section{HASIL PENELITIAN DAN PEMBAHASAN}

Dari 60 pasien Labioschisis dan Labiopalatoschisis, yaitu:

\section{Distribusi labioschisis}

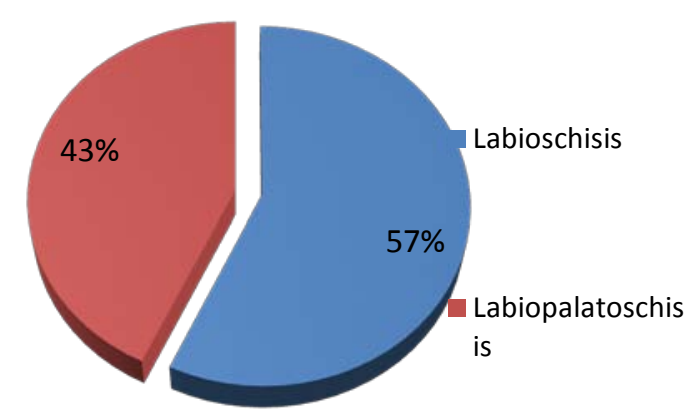

Ditemukan 43\% mencakup sumbing pada bibir dan langit - langit sebesar 26 pasien. Dan sumbing bibir tanpa disertai adanya sumbing langit - langit yaitu 34 pasien atau $57 \%$. 


\section{Distribusi jenis labioschisis}

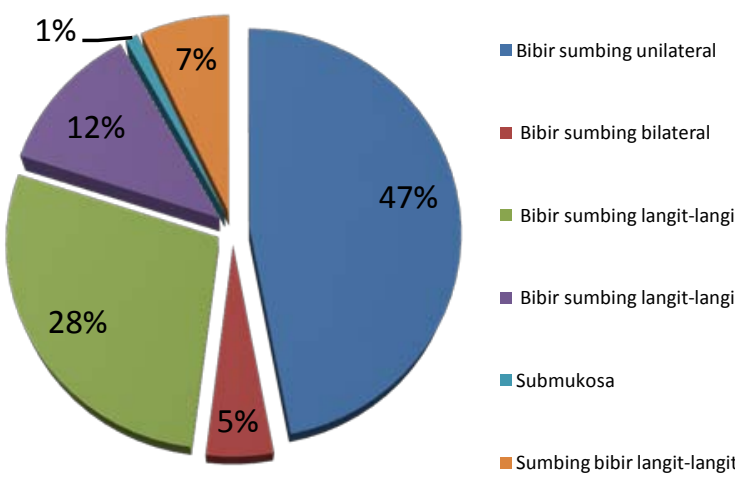

Distribusi usia penderita labioschisis waktu dilakukan operasi

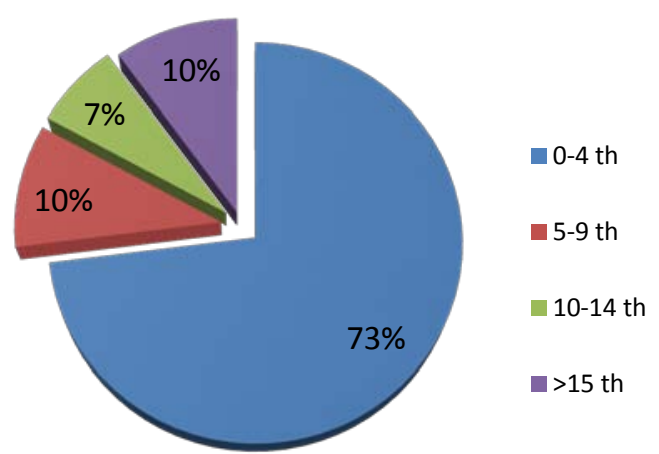

Diatas menunjukkan bahwa bibir sumbing unilateral adalah yang terbanyak sebesar 28 pasien atau 47\%, sumbing langit-langit unilateral sebesar 17 pasien atau $28 \%$, bibir sumbing langit-langit bilateral sebesar 7 pasien atau $12 \%$, sumbing bibir langit-langit sebesar 4 pasien atau $7 \%$, bibir sumbing bilateral sebesar 3 pasien atau $5 \%$, dan submukosa sebesar 1 pasien atau $1 \%$.

\section{Distribusi labioschisis menurut lokasi defek}

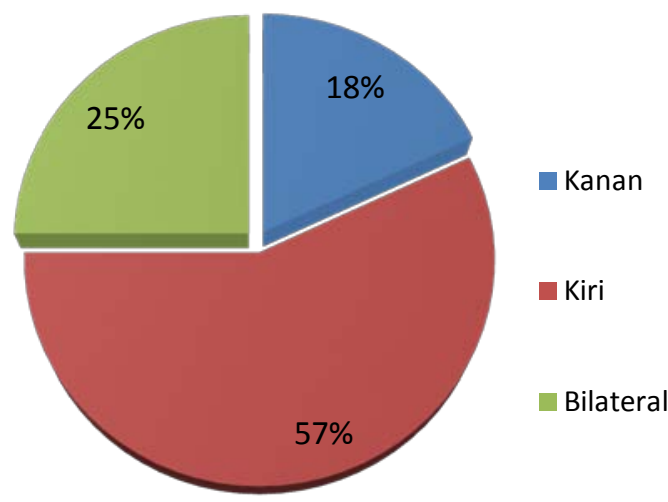

Lokalisasi defek Labioschisis ternyata lebih banyak diketahui, disini termasuk lokalisasi defek sebelah kiri terbanyak yaitu kiri 57\% atau sebesar 34 pasien, sebelah kanan 11 pasien atau $18 \%$, bilateral 15 pasien atau $25 \%$.

\section{Distribusi labioschisis menurut jenis kelamin}

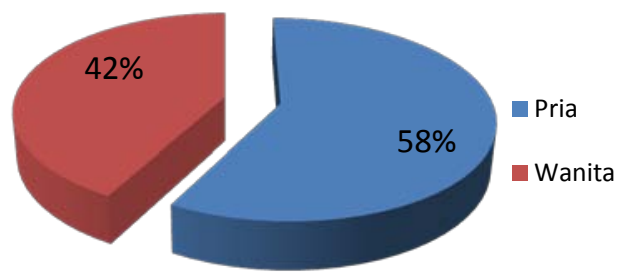

Tampak disini bahwa Labioschisis lebih banyak terjadi pada pria yaitu sebesar $58 \%$ atau 35 pasien, dari pada wanita $42 \%$ atau 25 pasien. Sesuai dengan kepustakaan bahwa pria lebih banyak menderita sumbing bibir. Selain itu, daerah yang terdapat banyak defek adalah pada sisi kiri karena pertumbuhan sisi kiri lebih lambat dari sisi kanan. 


\section{Distribusi labioschisis menurut etiologi}

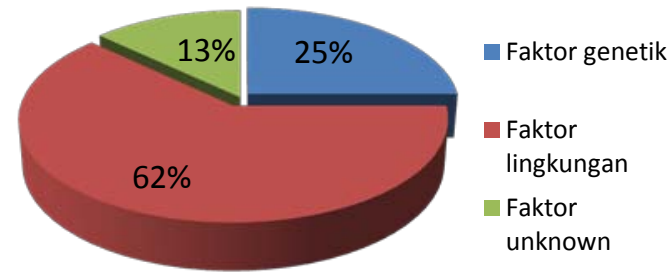

Berdasarkan etiologi yang diperoleh, ditemukan bahwa penyebab lingkungan memiliki presentase tertinggi yaitu $62 \%$ atau 37 pasien. Sedangkan penyebab genetik hanya $25 \%$ atau 15 pasein, dan penyebab unknown 13\% atau 8 pasien. Jadi saat ini sudah diketahui secara pasti penyebab dari kesumbingan tersebut.

\section{Distribusi jumlah pasien labioschisis yang dioperasi}

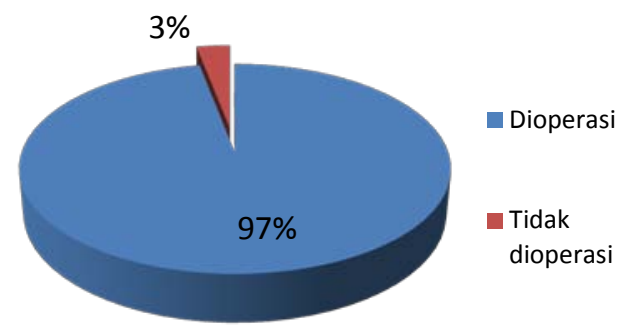

Dari 60 pasien yang masuk di BLU RSUP Prof. Dr. R. D. Kandou Manado periode Januari 2011-Oktober 2012 sebesar 97\% yaitu 58 pasien yang dioperasi dan sebesar 3\% yaitu 2 pasien yang tidak dioperasi oleh karena kelainan jantung.

\section{Distribusi labioschisis menurut komplikasi operasi}

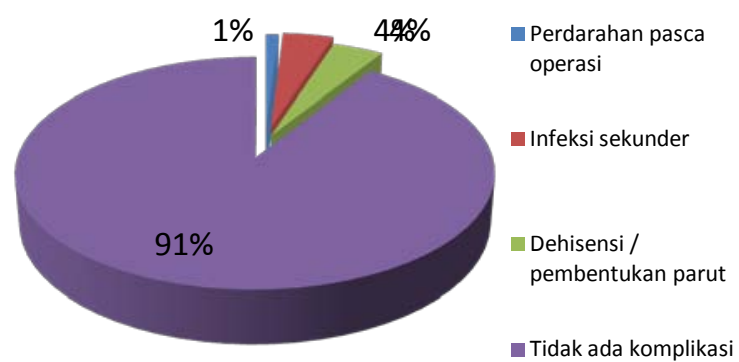

Terdapat 5 operasi, yaitu 1 operasi (1\%) yang mengalami perdarahan pascaoperasi, 2 operasi (4\%) mengalami infeksi sekunder, 2 operasi (4\%) mengalami dehisensi. Sedangkan 51 operasi (91\%) lainnya tidak mengalami komplikasi. Perdarahan biasanya terjadi oleh karena waktu operasi yang terlalu dini, infeksi sekunder terjadi karena faktor hygiene pasien yang kurang baik, dan pembentukan parut atau dehisensi adalah akibat tindakan kasar dengan peralatan yang tidak sesuai “keras”.

\section{SIMPULAN}

Berdasarkan penelitian selama periode Januari 2011-Oktober 2012, di Bagian Bedah RSUP. Prof. Dr. R. D. Kandou Manado ditemukan bahwa:

a. Bibir sumbing atau Labioschisis 34 kasus, serta kombinasi bibir sumbing dan langit-langit atau Labiopalatoschisis sebanyak 26 kasus, jadi jumlah total ada 60 kasus.

b. Bibir sumbing unilateral 30 dan bibir sumbing langit-langit unilateral 19 lebih banyak terjadi dibandingkan dengan bibir sumbing bilateral 3 dan bibir sumbing langit-langit bilateral 8.

c. Bibir sumbing dan bibir sumbing langitlangit lokalisasi defeknya lebih sering terjadi pada sisi kiri dari pada sisi kanan bilateral.

d. Umur penderita ketika dilakukan labioplasty terbanyak pada umur 0-4 tahun.

e. Bibir sumbing lebih sering terjadi pada Pria dari pada Wanita.

f. Faktor lingkungan adalah etiologi tersering.

g. 56 penderita yang dioperasi, dan hanya 4 penderita yang tidak dioperasi.

h. Ada 5 penderita yang mengalami komplikasi, yaitu Perdarahan pascaoperasi 1 penderita, Infeksi sekunder 2 penderita, dan dehisensi/pembentukan parut 2 penderita. 


\section{DAFTAR PUSTAKA}

1. Bibir Sumbing dan Celah pada Langit Mulut [homepage on the Internet]. Available from

http://detikhealth.com/health/read penyakit99/bibir-sumbing-dan-celah-padalangit-mulut/

2. Terjadinya Celah Bibir dan Celah Langit Bibir. 2012 Available from http://kedokterangigi.net/63/terjadinya celah-bibir-dan-celah-langit-langitbibir.html

3. Utama, H.S. Labiopalatoschizis dan Penanganannya. 2012 available from http://herryyudha.com/2012/06/labiopalatos hizis-dan-penanganannya.html

4. Natsir, F.M. Cleft palate. 2011 available from

http://fathirphoto.wordpress.com/2011/11/0 3/palatoschisis-cleft-palate/

5. Pearce EC. Anatomi dan Fisiologi Untuk Paramedis, Jakarta : Penerbit PT Gramedia Pustaka Utama. $1990: 177-178$.

6. Sjamsuhidajat, R., Wim De Jong. Labioschisis. Buku Ajar Ilmu Bedah. 1996.Jakarta.(2):344-45.

7. Ngantung J. Bahan Kuliah Bibir Sumbing. Devisi Bedah Plastik RSUP Prof. Dr. R. D. Kandou. FK UNSRAT : 2012.

8. Fawzy, A. Bibir Sumbing. 2007. Available from http://.bedah-plastik.com/cleft/html

9. Udiyana, D.M. Bibir Sumbing kelainan bawaan ataukah keturunan. 2012. Available from http://kobarnews.com/inside/bibirsumbing-kelainan-bawaan-ataukahketurunan.html.

10. Etna. Plastic and Craniofacial Surgery for infans and children. Cleft lip palate. Medical web site design \& medical marketing. Available from www.kidsplastsurg.com

11. Washito, A. Embriologi cleft lip and palate. 2010:(27) page 789. Available from http://embriologi-cleft-lip-and-palate.com

12. Ngantung J. Bahan Kuiah Embriologi Bibir Sumbing. Devisi Bedah Plastik RSUP Prof. Dr. R. D. Kandou. FK UNSRAT : 2012.

13. Townsend, C.M., Beauchamp, R.D., Evers, B.M., Mattox, L.K. Palatoschisis dan labioschisis. Buku saku ilmu bedah sabiston.penerbit buku kedokteran EGC:(17) page 1022.

14. Karina, N. Bibir sumbing Available from. http://www.tanyadok.com/anak/kenapabibir-bisa-sumbing. Download on Nov 7, 2011.

15. Priyanto, D. Kemampuan bicara penderita celah bibir dan langit-langit. 2010 Availabel from. http://suaramerdeka.com

16. Pretorius, D.H., House, M., Nelson, T., Hollenback, K.A. 1995. Evaluation of normal and abnormal lips in fetuses. Comparison between three and two dimensional sonography.(5) 1233-37.

17. Tompson, B., Posnick, J.C., Cleft orthognathic surgery. Complication and long-term result. 1995-1996 (2) 255-66. 